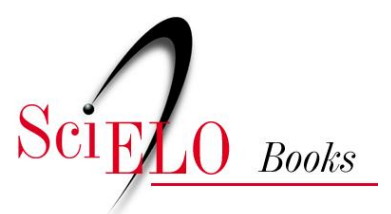

\title{
Ordem Tetraodontiformes
}

\author{
Ana Cristina Teixeira Bonecker \\ Claudia Akemi Pereira Namiki \\ Márcia Salustiano de Castro \\ Paula Nepomuceno Campos
}

\section{SciELO Books / SciELO Livros / SciELO Libros}

BONECKER, ACT., et al. Ordem Tetraodontiformes. In Catalogo dos estágios iniciais de desenvolvimento dos peixes da bacia de Campos [online]. Curitiba: Sociedade Brasileira de Zoologia, 2014, pp. 276-283. Zoologia: guias e manuais de identificação series. ISBN 978-85-98203-10-2.

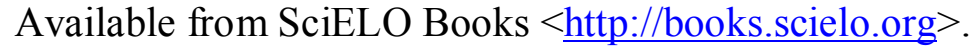

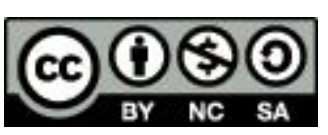

All the contents of this chapter, except where otherwise noted, is licensed under a Creative Commons Attribution-Non Commercial-ShareAlike 3.0 Unported.

Todo o conteúdo deste capítulo, exceto quando houver ressalva, é publicado sob a licença Creative Commons Atribuição Uso Não Comercial - Partilha nos Mesmos Termos 3.0 Não adaptada.

Todo el contenido de este capítulo, excepto donde se indique lo contrario, está bajo licencia de la licencia Creative Commons Reconocimento-NoComercial-CompartirIgual 3.0 Unported. 


\section{ORDEM TETRAODONTIFORMES}

A ordem Tetraodontiformes é composta por nove famílias e 357 espécies. O corpo pode ser arredondado ou moderadamente alongado. As larvas possuem um saco dermal ou epiderme inflada, grupo de espinhos no opérculo e espinhos ou placas dérmicas na superfície do corpo. As nadadeiras dorsal e anal estão situadas na porção posterior do corpo com exceção da família Monacanthidae.

Nesse estudo a ordem Tetraodontiformes é representada pelas famílias Monacanthidae, Ostraciidae e Tetraodontidae. 


\section{Família Monacanthidae}

A família Monacanthidae é marinha e ocorre nos oceanos Atlântico, Índico e Pacífico. Compreende 32 gêneros com 102 espécies. As larvas possuem o corpo alto ou alongado em algumas espécies. O corpo é muito comprimido com espinhos minúsculos e as nadadeiras pélvicas são ausentes. Possuem grupos de espinhos no pré-opérculo, pequenos espinhos dermais na área interorbital, melanóforos na cabeça e uma série de melanóforos na região ventral ao longo da cauda. O primeiro espinho dorsal é alongado com projeções dos dois lados, o segundo é muito menor e pode estar ausente.

No Brasil já foram identificadas nove espécies nas fases de larva e adulto. Nesse estudo é contemplada a espécie Monacanthus ciliatus. 


\section{Monacanthus ciliatus (Mitchill, 1818)}

As larvas no estágio de pré-flexão possuem o corpo alto e muito comprimido e focinho relativamente curto, que fica projetado, mas não muito alongado nos estágios de desenvolvimento seguintes. Possui um total de 19 miômeros. Tem dois espinhos dorsais, sendo que o primeiro se origina na parte posterior do olho. O espinho pélvico é bem desenvolvido, com denticulações curtas. Tem espinhos pequenos ao longo do corpo. O padrão de pigmentação é bem característico. Nas larvas em pré-flexão os melanóforos estão espalhados pela cabeça, sobre todo o cérebro alcançando a região ocular, no peritônio, sobre a vesícula gasosa e trato digestório. A partir da flexão surgem melanóforos no primeiro

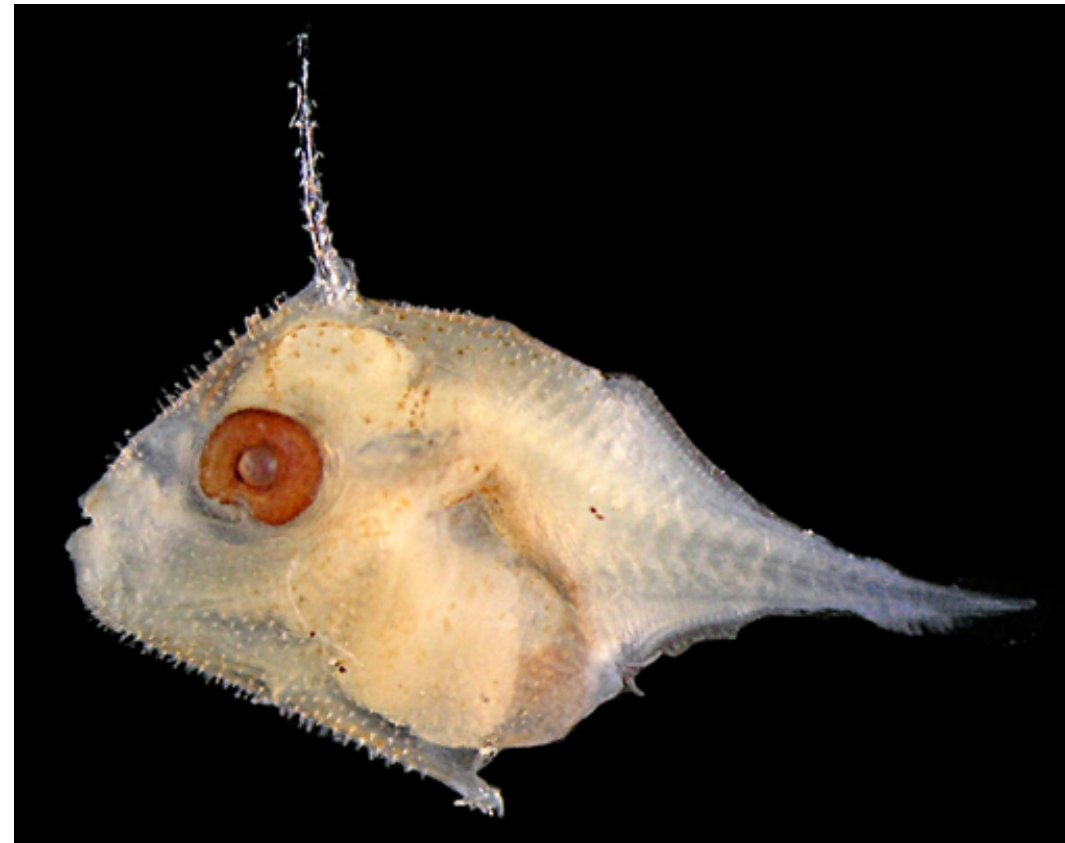

Figura 157-A: Monacanthus ciliatus. DZUFRJ 472; Pré-flexão; CP 4,1 mm. espinho dorsal e a pigmentação da cabeça e do corpo se intensificam. A linha de pigmentos sobre a linha lateral, na região posterior do corpo, se expande em direção a região anterior. Nadadeira dorsal: II + 29-37; nadadeira anal: 28-36.

Tamanho: pré-flexão 2,44,1 mm; flexão 4,5-5,2 mm; transformação $12,0 \mathrm{~mm}$.

Habitat: espécie marinha, demersal, associada a formações coralinas, ocorre até $50 \mathrm{~m}$ de profundidade.

Nome vulgar: Porquinho de franja.

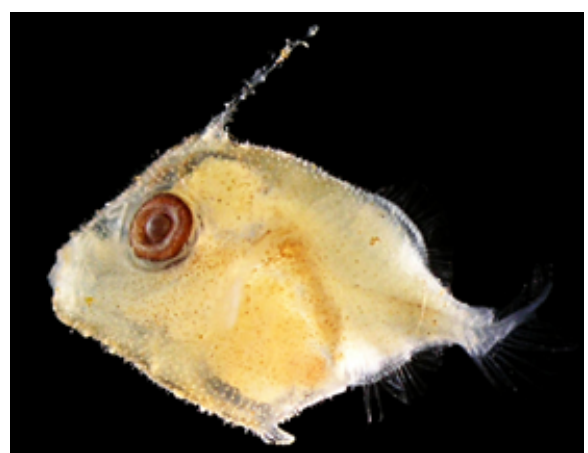

Figura 157 - B: DZUFRJ 472; Flexão; CP 5,0 mm.

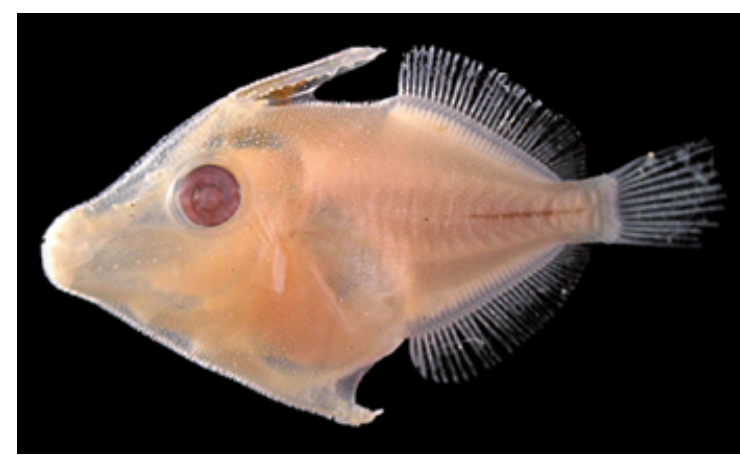

Figura 157 - C: DZUFRJ 19890; Transformação; CP 12,0 mm.

\section{Georreferenciamento}

\begin{tabular}{|c|c|c|c|c|c|c|c|c|}
\hline DZUFRJ & Latitude (S) & Longitude (W) & Data & $\begin{array}{l}\text { Tipo de } \\
\text { arrasto }\end{array}$ & $\begin{array}{l}\text { Profundidade } \\
\text { de coleta }\end{array}$ & Rede & $\begin{array}{l}\text { Malha } \\
(\mu \mathrm{m})\end{array}$ & $\begin{array}{l}\text { No. de } \\
\text { inds. }\end{array}$ \\
\hline 465 & $22^{\circ} 36^{\prime} 54,9^{\prime \prime}$ & $040^{\circ} 09^{\prime} 19,4^{\prime \prime}$ & $16 / 05 / 2002$ & oblíquo & $50 \mathrm{~m}$ & bongô & 500 & 1 \\
\hline 469 & $22^{\circ} 37^{\prime} 35,5^{\prime \prime}$ & $040^{\circ} 09^{\prime} 32,8^{\prime \prime}$ & $16 / 05 / 2002$ & oblíquo & $1.000 \mathrm{~m}$ & ilíndrico-cônica & 500 & 1 \\
\hline 472 & $22^{\circ} 36^{\prime} 54,9^{\prime \prime}$ & $040^{\circ} 09^{\prime} 19,4^{\prime \prime}$ & $16 / 05 / 2002$ & oblíquo & $50 \mathrm{~m}$ & bongô & 330 & 5 \\
\hline 473 & $22^{\circ} 42^{\prime} 06,0^{\prime \prime}$ & $040^{\circ} 14^{\prime} 26,0^{\prime \prime}$ & 19/05/2002 & oblíquo & $50 \mathrm{~m}$ & bongô & 330 & 1 \\
\hline 478 & $22^{\circ} 33^{\prime} 37,0^{\prime \prime}$ & $040^{\circ} 19^{\prime} 10,0^{\prime \prime}$ & $17 / 05 / 2002$ & oblíquo & $50 \mathrm{~m}$ & bongô & 500 & 2 \\
\hline 19889 & $21^{\circ} 53^{\prime} 10,4^{\prime \prime}$ & $039^{\circ} 45^{\prime} 49,9^{\prime \prime}$ & 10/10/2001 & oblíquo & $1.000 \mathrm{~m}$ & cilíndrico-cônica & 500 & 1 \\
\hline 19890 & $22^{\circ} 32^{\prime} 50,0^{\prime \prime}$ & $040^{\circ} 04^{\prime} 09,9^{\prime \prime}$ & $06 / 11 / 2001$ & oblíquo & $1.000 \mathrm{~m}$ & cilíndrico-cônica & 500 & 1 \\
\hline 19891 & $22^{\circ} 35^{\prime} 08,5^{\prime \prime}$ & $039^{\circ} 46^{\prime} 22,3^{\prime \prime}$ & $06 / 12 / 2$ & vertical & 50 & cônica & 200 & 1 \\
\hline 19910 & $22^{\circ} 02^{\prime} 35,2^{\prime \prime}$ & $039^{\circ} 43^{\prime} 18,2^{\prime \prime}$ & $04 / 12 / 2002$ & vertical & $700-1.200 m$ & cilíndrico-cônica & 500 & 2 \\
\hline
\end{tabular}

Referências: Watson, 1996m; Barros et al., 2006b; Zapfe \& Lyczkowski-Shultz, 2006; Fahay, 2007. 


\section{Família Ostraciidae}

A família Ostraciidae é marinha e ocorre nos oceanos Atlântico, Índico e Pacífico. Compreende 14 gêneros com 33 espécies. As larvas possuem o corpo muito arredondado coberto por uma carapaça óssea desde os estágios iniciais de desenvolvimento. As nadadeiras dorsal e anal são curtas (9-13 raios) e estão posicionadas na região posterior do corpo.

No Brasil já foram identificadas cinco espécies nas fases de larva e adulto: Acanthostracion polygonius Poey, 1876; Acanthostracion quadricornis (Linnaeus, 1758); Lactophrys bicaudalis (Linnaeus, 1758); Lactophrys trigonus (Linnaeus, 1758) e Lactophrys triqueter (Linnaeus, 1758). Nesse estudo é contemplada a espécie Acanthostracion sp. 


\section{Acanthostracion sp.}

As larvas de Acanthostracion possuem a parte anterior do corpo arredondada e a parte posterior mais fina. Uma carapaça cobre a parte anterior do corpo e está completamente formada até o final da flexão. Distância pré-anal aproximadamente $65 \%$ do corpo. A pigmentação é intensa na parte anterior do corpo e ausente na cauda. As nadadeiras dorsal e anal são pequenas e estão situadas na parte posterior do corpo, na mesma direção. Raios da nadadeira dorsal: 10; raios da nadadeira anal: 10.

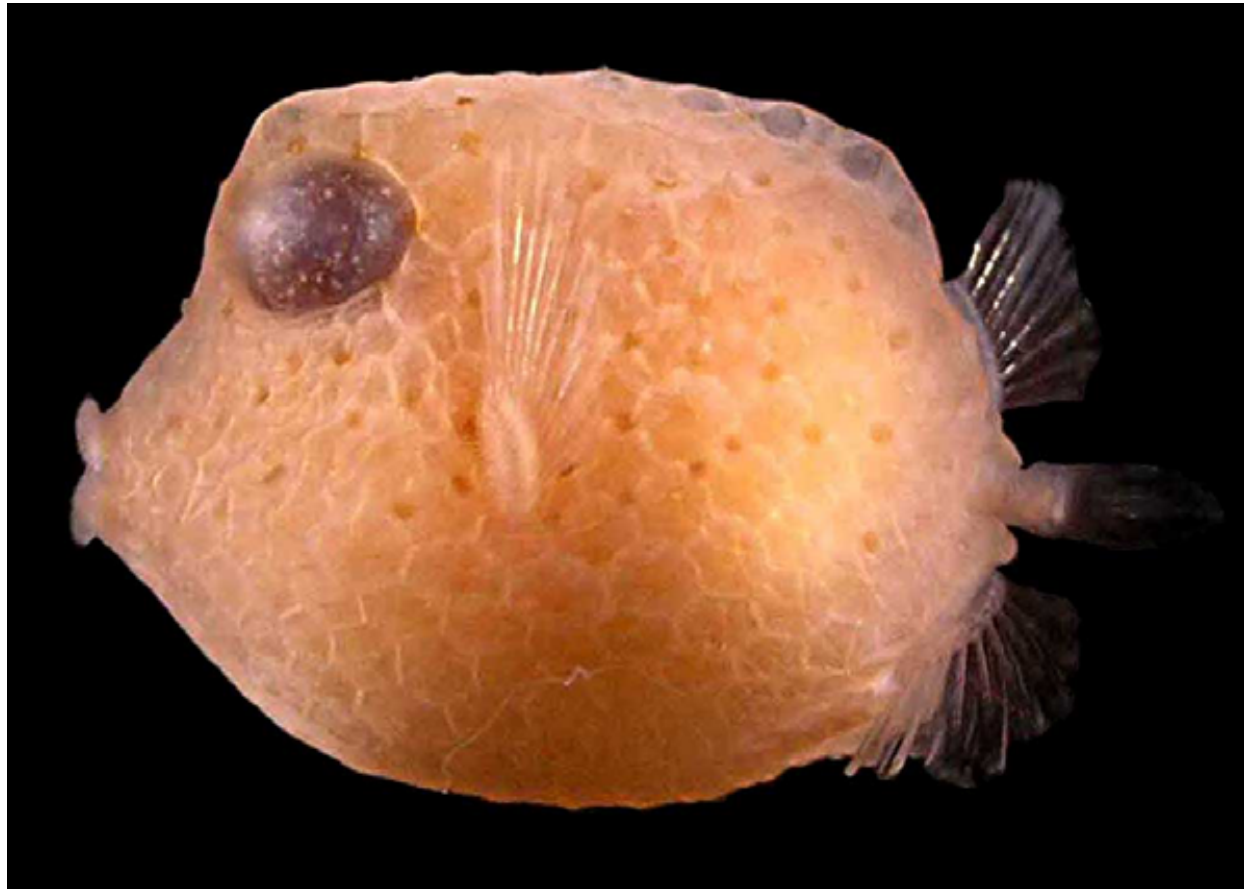

Figura 158 - Acanthostracion sp. DZUFRJ 5506; Transformação; CP 10,0 mm.

Tamanho: transformação 10,0 mm.

Habitat: todas as espécies são marinhas e demersais, associadas a formações coralinas, ocorrem até $200 \mathrm{~m}$ de profundidade.

No Brasil já foram registradas as espécies Acanthostracion polygonius Poey, 1876 e Acanthostracion quadricornis (Linnaeus, 1758).

\section{Georreferenciamento}

\begin{tabular}{|c|c|c|c|c|c|c|c|c|}
\hline DZUFRJ & Latitude (S) & Longitude (W) & Data & $\begin{array}{c}\text { Tipo de } \\
\text { arrasto }\end{array}$ & $\begin{array}{c}\text { Profundidade } \\
\text { de coleta }\end{array}$ & Rede & $\begin{array}{c}\text { Malha } \\
(\mu \mathrm{\mu m})\end{array}$ & $\begin{array}{c}\mathbf{N}^{\circ} \text {. de } \\
\text { inds. }\end{array}$ \\
\hline 5506 & $22^{\circ} 32^{\prime} 499^{\prime \prime}$ & $040^{\circ} 04^{\prime} 20,9^{\prime \prime}$ & $07 / 11 / 2001$ & oblíquo & $1.000 \mathrm{~m}$ & cilíndrico-cônica & 500 & 1 \\
\hline
\end{tabular}

Referências: Barros et al., 2006b; Lyczkowski-Shultz et al., 2006, Fahay, 2007. 


\section{Família Tetraodontidae}

A família Tetraodontidae é marinha, com algumas espécies habitantes de formações coralinas e várias espécies vivem em água salobra e doce. Ocorre nas regiões tropicais e subtropicais, nos oceanos Atlântico, Índico e Pacífico. Compreende 19 gêneros e aproximadamente 130 espécies.

Os representantes dessa família são caracterizados pelo formato do corpo e pela capacidade de inflá-lo, engolindo água ou ar. A maioria das espécies possui o corpo oval com espinhos cobrindo a porção ventral do corpo. Não possuem nadadeira pélvica e as nadadeiras dorsal e anal são curtas e opostas. A pigmentação do corpo varia muito de acordo com as espécies, estando presente na margem dorsal do intestino, cabeça e tronco e aumentando com o desenvolvimento da larva.

No Brasil já foram identificadas 13 espécies. Nesse estudo são contempladas as espécies Canthigaster rostrata e Lagocephalus lagocephalus. 


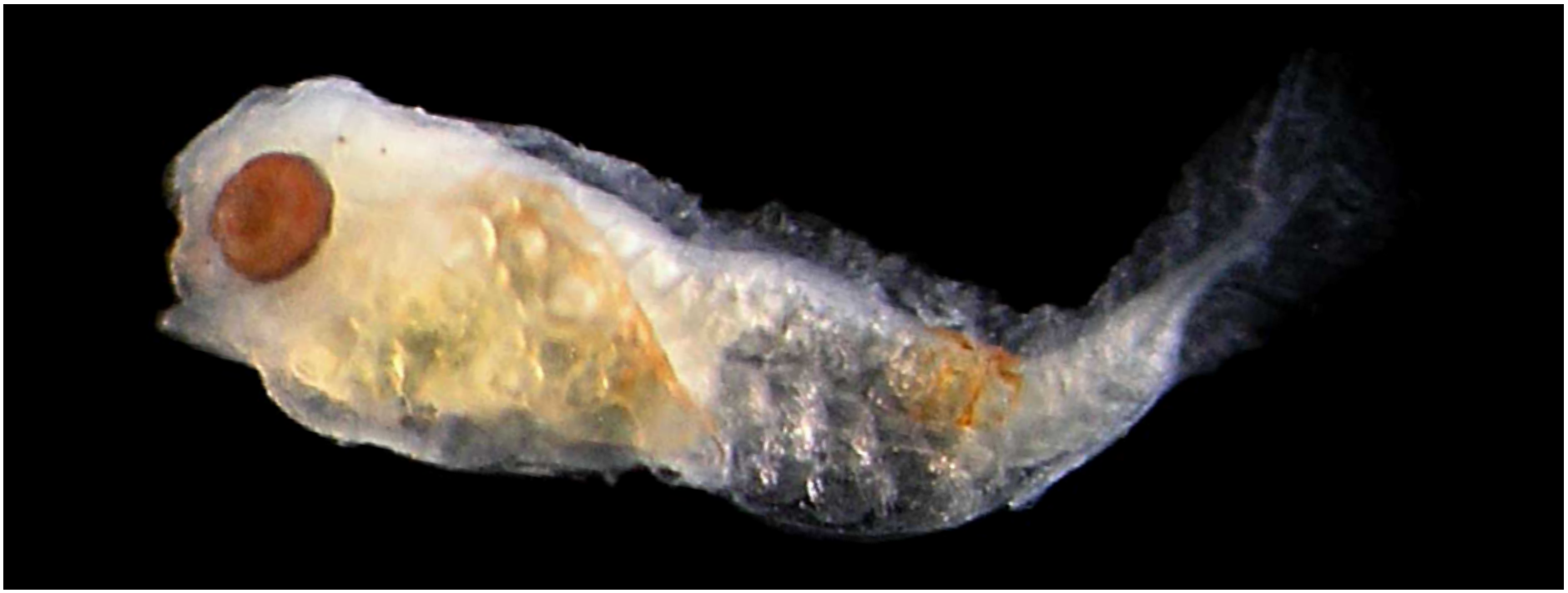

Figura 159 - A: Canthigaster rostrata. A. DZUFRJ 22509; Pré-flexão; 2,0 mm.

\section{Canthigaster rostrata (Bloch, 1786)}

O corpo é arredondado e pouco comprimido lateralmente. As larvas no estágio de pré-flexão já possuem espinhos distribuídos por todo corpo. As espécies podem ser separadas pelo número de raios nas nadadeiras. A dorsal é formada por dez raios e a anal por nove raios. Desde a pré-flexão apresenta uma faixa vertical de pigmentos, entre os miômeros 12 e 15. Com o desenvolvimento, uma banda horizontal se forma no corpo, desde a margem ventral da nadadeira caudal até a base da nadadeira anal. Possui um total de 17 vértebras.

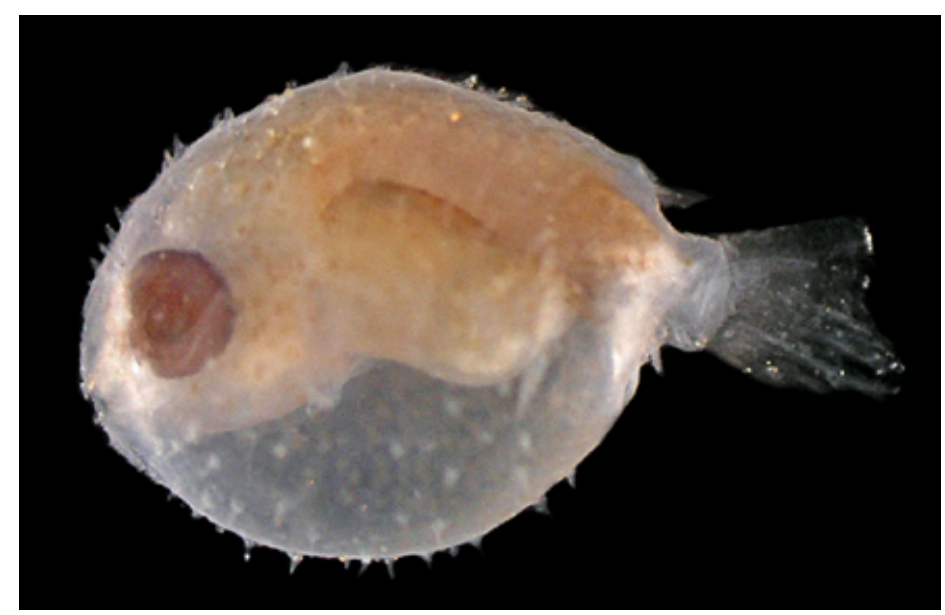

Figura 159 - B: DZUFRJ 5504; Flexão; CP 7,0 mm.

Tamanho: pré-flexão 2,0 mm; flexão 7,0 mm.

Habitat: espécie marinha, demersal, associada a formações coralinas, ocorre até $40 \mathrm{~m}$ de profundidade.

Nome vulgar: Baiacu.

\section{Georreferenciamento}

\begin{tabular}{|c|c|c|c|c|c|c|c|c|}
\hline DZUFRJ & Latitude (S) & Longitude (W) & Data & $\begin{array}{c}\text { Tipo de } \\
\text { arrasto }\end{array}$ & $\begin{array}{c}\text { Profundidade } \\
\text { de coleta }\end{array}$ & Rede & $\begin{array}{c}\text { Malha } \\
\text { ( } \boldsymbol{\mu m})\end{array}$ & $\begin{array}{c}\mathbf{N}^{\circ} \text {. de } \\
\text { inds. }\end{array}$ \\
\hline 5503 & $22^{\circ} 31^{\prime} 40,9^{\prime \prime}$ & $040^{\circ} 02^{\prime} 39,6^{\prime \prime}$ & $07 / 11 / 2001$ & oblíquo & $1.000 \mathrm{~m}$ & cilíndrico-cônica & 500 & 1 \\
\hline 5504 & $22^{\circ} 32^{\prime} 50,0^{\prime \prime}$ & $040^{\circ} 04^{\prime} 09,9^{\prime \prime}$ & $06 / 11 / 2001$ & oblíquo & $1.000 \mathrm{~m}$ & cilíndrico-cônica & 500 & 1 \\
\hline 22509 & $22^{\circ} 32^{\prime} 03,0^{\prime \prime}$ & $040^{\circ} 17^{\prime} 21,0^{\prime \prime}$ & $19 / 05 / 2002$ & oblíquo & $30 \mathrm{~m}$ & bongô & 330 & 2 \\
\hline
\end{tabular}

Referências: Figueiredo \& Menezes, 2000; Moura \& Castro, 2002; Shipp, 2002; Barros et al., 2006b; Lyczkowski-Shultz, 2006; Froese \& Pauly, 2014. 


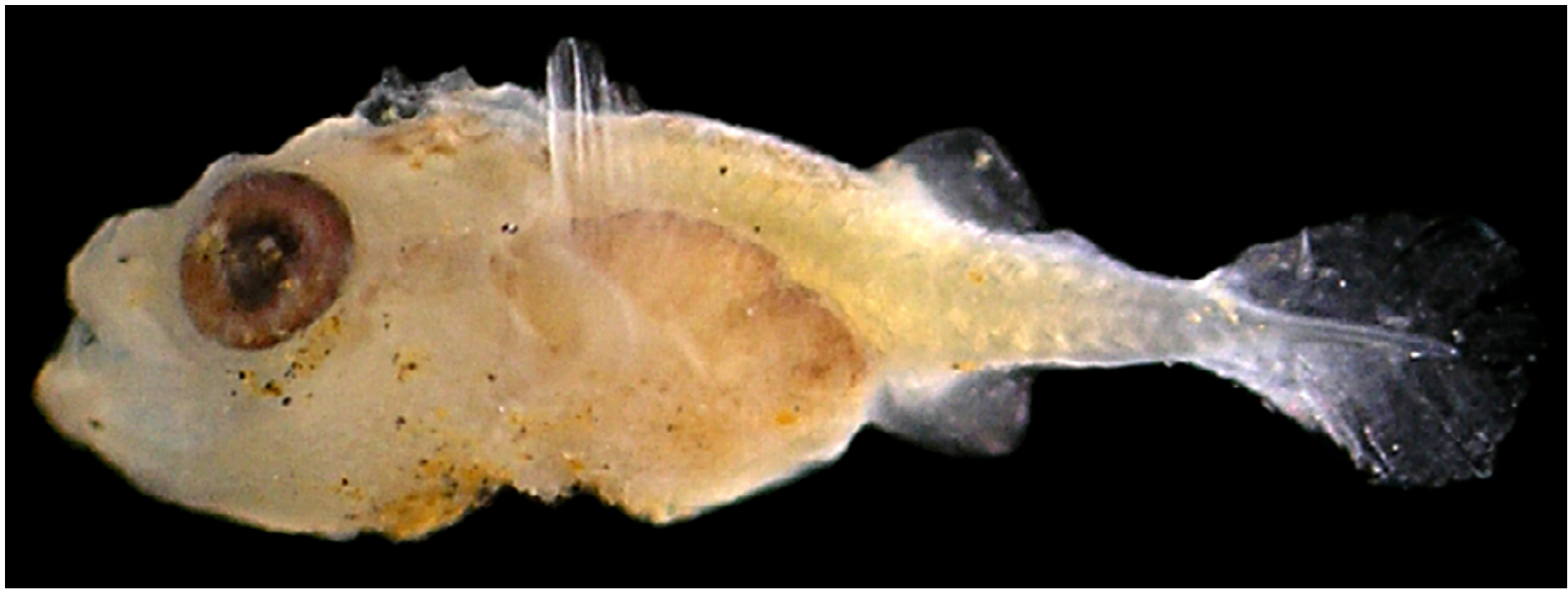

Figura 160 - A: Lagocephalus lagocephalus. DZUFRJ 430; Pré-flexão; CP 3,2 mm.

\section{Lagocephalus lagocephalus (Linnaeus, 1758)}

O corpo é arredondado e possui espinhos por toda região ventral. As nadadeiras dorsal e anal estão situadas na região posterior do corpo. Possui melanóforos espalhados pela região dorso-lateral do corpo e do trato digestório desde o estágio de pré-flexão.

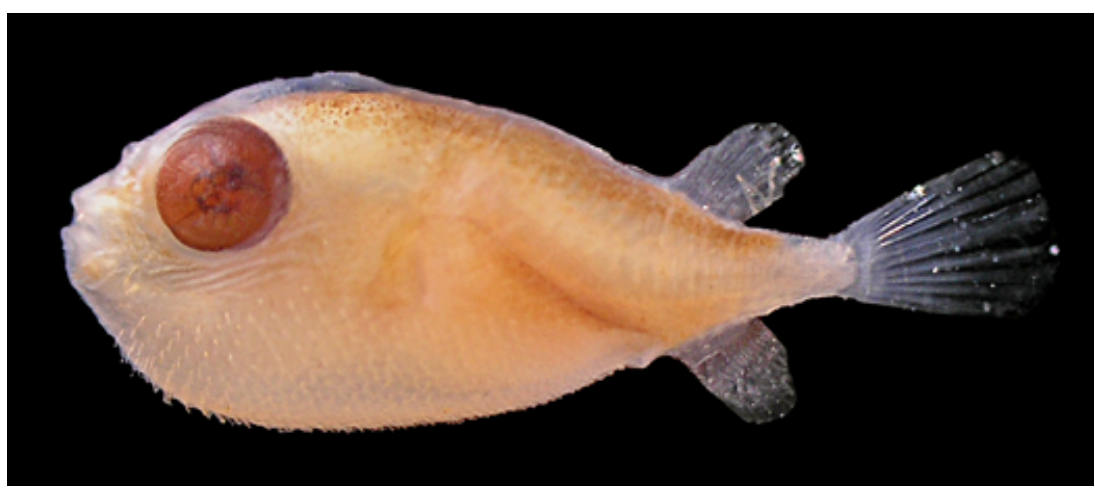

Figura 160 - B: DZUFRJ 7505; Flexão; CP 7,0 mm.

A pigmentação dorso-lateral se intensifica ao longo do desenvolvimento. Nadadeira dorsal: 13-16 raios; nadadeira caudal: 12-13 raios; nadadeira peitoral: 14-16 raios. Possui um total de 18 vértebras.

Tamanho: pré-flexão 1,8-3,2 mm; flexão 7,0-8,0 mm.

Habitat: espécie marinha, demersal, ocorre entre 10 e 476 m de profundidade.

Nome vulgar: Baiacu.

\section{Georreferenciamento}

\begin{tabular}{|c|c|c|c|c|c|c|c|c|}
\hline DZUFRJ & Latitude (S) & Longitude (W) & Data & $\begin{array}{c}\text { Tipo de } \\
\text { arrasto }\end{array}$ & $\begin{array}{c}\text { Profundidade } \\
\text { de coleta }\end{array}$ & Rede & $\begin{array}{c}\text { Malha } \\
\text { ( } \boldsymbol{\mu m})\end{array}$ & $\begin{array}{c}\mathbf{N}^{\circ} \text {. de } \\
\text { inds. }\end{array}$ \\
\hline 429 & $22^{\circ} 32^{\prime} 03,0^{\prime \prime}$ & $040^{\circ} 17^{\prime} 21,0^{\prime \prime}$ & $19 / 05 / 2002$ & oblíquo & $30 \mathrm{~m}$ & bongô & 330 & 2 \\
\hline 426 & $22^{\circ} 38^{\prime} 29,0^{\prime \prime}$ & $040^{\circ} 17^{\prime} 40,0^{\prime \prime}$ & $18 / 05 / 2002$ & oblíquo & $800 \mathrm{~m}$ & cilíndrico-cônica & 500 & 1 \\
\hline 427 & $22^{\circ} 31^{\prime} 27,0^{\prime \prime}$ & $040^{\circ} 16^{\prime} 56,0^{\prime \prime}$ & $17 / 05 / 2002$ & oblíquo & $600 \mathrm{~m}$ & cilíndrico-cônica & 500 & 1 \\
\hline 428 & $22^{\circ} 34^{\prime} 05,0^{\prime \prime}$ & $040^{\circ} 19^{\prime} 40,0^{\prime \prime}$ & $17 / 05 / 2002$ & oblíquo & $600 \mathrm{~m}$ & cilíndrico-cônica & 500 & 2 \\
\hline 430 & $22^{\circ} 33^{\prime} 37,0^{\prime \prime}$ & $040^{\circ} 19^{\prime} 10,0^{\prime \prime}$ & $17 / 05 / 2002$ & oblíquo & $50 \mathrm{~m}$ & bongô & 330 & 2 \\
\hline 5505 & $22^{\circ} 32^{\prime} 50,0^{\prime \prime}$ & $040^{\circ} 04^{\prime} 09,9^{\prime \prime}$ & $06 / 11 / 2001$ & oblíquo & $1.000 \mathrm{~m}$ & cilíndrico-cônica & 500 & 1 \\
\hline 7505 & $21^{\circ} 54^{\prime} 36,5^{\prime \prime}$ & $039^{\circ} 45^{\prime} 20,0^{\prime \prime}$ & $09 / 10 / 2001$ & oblíquo & $1.000 \mathrm{~m}$ & cilíndrico-cônica & 500 & 1 \\
\hline
\end{tabular}

Referências: Figueiredo \& Menezes, 2000; Shipp, 2002; Barros et al., 2006b; Lyczkowski-Shultz, 2006; Froese \& Pauly, 2009. 